\title{
Realising the potential of radioligand therapy: policy solutions for the barriers to implementation across Europe
}

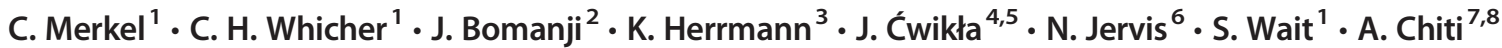

Published online: 13 March 2020

(C) The Author(s) 2020

\section{Background}

The use of targeted radiation with radioisotopes has been applied for decades in thyroid cancer. However, the use of radioligand therapy - also referred to as peptide-receptor radionuclide therapy (PRRT), systemic radiation therapy, targeted radionuclide therapy (TRT), targeted radiotherapy or molecular radiotherapy-is now gaining ground more broadly in oncology. Therapies have been approved for a small number of cancers where few treatment options exist, such as midgut neuroendocrine tumours and metastatic castration-resistant prostate cancer (mCRPC) $[1,2]$, and they have been shown to improve progression-free survival and quality of life for many patients [3-7]. The approach is also being explored in other cancer and non-cancer conditions.

Nuclear medicine has, traditionally, sat somewhat on the sidelines of cancer care; however, the evolving oncology landscape suggests its role will grow, with broader applications in both diagnostics and therapy [8]. Nuclear medicine specialists will need to be fully integrated into multidisciplinary cancer care teams, and appropriate resourcing to deliver radioligand therapy - in terms of hospital infrastructure and workforce, as

This article is part of the Topical Collection on Editorial

All authors were responsible for the concept, design, data acquisition and review of the manuscript. CM, CW and SW were responsible for data analysis and interpretation, and the preparation and editing of the manuscript. All authors read and approved the final manuscript.

C. Merkel

Christine.Merkel@hpolicy.com

The Health Policy Partnership, London, UK

2 Institute of Nuclear Medicine UCLH NHS Foundation Trust, London, UK

3 Clinic for Nuclear Medicine, Essen University Hospital, Essen, Germany well as nuclear waste facilities-will need to be taken into account in future cancer plans and care pathways.

Over the course of 2019, we conducted desk research and semi-structured expert interviews to explore potential barriers to achieving this integration in practice, drawing on insights from five different countries - Germany, Italy, Poland, Spain and the United Kingdom. The resulting document, 'Radioligand therapy: realising the potential of targeted cancer care', [9] was launched at the European Parliament in January 2020 along with an accompanying video explaining radioligand therapy for a lay audience. This report is an important reminder to the fields of nuclear medicine and oncology of the factors necessary to ensure advances in nuclear medicine reach patients in future models of cancer care.

\section{What are the potential barriers to integration of radioligand therapy into cancer care?}

Healthcare systems are often inadequately prepared for greater utilisation and integration of radioligand therapy. The report identified six key barriers to the greater integration of
4 Department of Cardiology and Cardiac Surgery, Medical School University of Warmia and Mazury, Olsztyn, Poland

5 Diagnostic and Therapy Center, Warsaw, Poland

6 Neuroendocrine Cancer UK, Leamington Spa, UK

7 Department of Biomedical Sciences, Humanitas University, Milan, Italy

8 Unit of Nuclear Medicine, Humanitas Research Hospital, Milan, Italy 
radioligand therapy into cancer care: low awareness and understanding; limited professional capacity, training and workforce planning; unclear models of care; inadequate physical capacity and resourcing in hospitals; evolving legislation, regulation and policy; and lack of data and research [9].

\section{Low awareness and understanding}

Many oncologists and other clinicians engaged in cancer care may not fully understand what radioligand therapy is. Moreover, patients - and sometimes clinicians too - may be wary due to negative preconceptions around the use of radioactive substances $[10,11]$.

\section{Limited professional capacity, training and workforce planning}

Different countries, and even different hospitals in the same country, often have disparate ways of organising the delivery of radioligand therapy [12]. Generally, there are few healthcare personnel appropriately trained in this treatment approach [10], restricting it to a small number of specialist centres.

Despite being a tenet of most clinical guidelines and cancer plans, multidisciplinary working is not always implemented in practice. Roles and responsibilities of different members of the multidisciplinary team can be unclear $[11,13]$; this holds true particularly for the inclusion of nuclear medicine specialists in tumour boards in non-specialist hospitals. In some centres, the limited number of nuclear medicine specialists may simply mean there is not enough capacity for them to participate in every multidisciplinary tumour board.

Educating all members of the multidisciplinary cancer team on radioligand therapy is important, as mentioned above; however, there seem to be few consistent educational initiatives appropriate to the whole cancer care team.

\section{Unclear models of care}

The provision of radioligand therapy requires intensive planning with clear workflows and processes $[10,14,15]$. New processes around radioligand therapy may be disruptive to current cancer care pathways, which may be a barrier in itself [10]. Greater harmonisation of guidelines and treatment protocols is also a challenge with radioligand therapy, causing inconsistencies in practice. As the evidence base evolves, both guidelines and models of care need to be updated in line with the latest scientific advances $[16,17]$.

\section{Inadequate physical capacity and resourcing in hospitals}

There are significant geographical variations in access to radioligand therapy, meaning people often travel significant distances, and even across countries, for treatment [10]. The approach is frequently provided as an inpatient procedure, which may require isolation of patients in lead-lined rooms in line with local legislation - and existing treatment centres may not have sufficient capacity to meet patient needs. There may be also additional requirements for equipment or storage facilities for contaminated materials. In some centres, moving to an outpatient model is being explored to potentially alleviate some of these capacity issues, as not all radiopharmaceuticals require a strict hospital regime.

As demand for all types of radioisotopes continues to grow, sustained efforts are needed from both the health and energy sectors to ensure consistent supply and delivery. Most medical radioisotopes are created in a small number of nuclear reactors, which are becoming increasingly unreliable due to old age [18-20]. There can be additional logistical difficulties in post-production processing and distribution to hospitals [18-21]. Such unpredictability in the global supply chain has directly impacted availability of diagnostic tests and medical procedures involving certain radioisotopes $[18,20]$.

\section{Evolving legislation, regulation and policy}

Regulatory frameworks for approval of radioligand therapy are inconsistent between countries-in some instances radioligands are considered pharmaceuticals, in others they are classified and regulated as radioactive substances. Furthermore, regulatory frameworks do not fully account for differences between radioisotopes, for example, between diagnostic radioisotopes and therapeutic radioisotopes in which alpha or beta radiation is the main energy carrier. Such rigid frameworks can restrict the use of certain types of radioligand therapy and affect who provides treatment and how [11, 15, 22]. Both international and national regulatory frameworks developed for conventional medicines may need to be adapted to be appropriate for the evaluation of radioligand therapy and radioisotopes [23].

Waste disposal policies also need careful planning, as different radioisotopes require different processes [14]. Although some radioisotopes do not require significant specialised waste collection or storage, these processes may be required in other cases; a 'one size fits all' nuclear waste disposal policy is therefore not appropriate. As demand increases, there may be additional pressures on such processes.

\section{Lack of data and research}

The limited availability of representative clinical data on radioligand therapy poses a challenge [12], potentially contributing to significant disparities in availability across Europe [10, 24]. The absence of clear and consistent understanding of what constitutes a response to radioligand 
Table 1 Key actions to overcome the barriers to greater integration of radioligand therapy in clinical cancer care

\begin{tabular}{|c|c|}
\hline Barrier & Action needed \\
\hline Low awareness and understanding & $\begin{array}{l}\text { - Increase awareness of radioligand therapy and the role of nuclear medicine among decision-makers, } \\
\text { people with cancer and the clinical cancer community. }\end{array}$ \\
\hline $\begin{array}{l}\text { Limited professional capacity, } \\
\text { training and workforce planning }\end{array}$ & $\begin{array}{l}\text { - Harmonise education and training standards across Europe for nuclear medicine specialists and all } \\
\text { members of the multidisciplinary cancer team. } \\
\text { - Ensure that nuclear medicine specialists have adequate capacity to participate in multidisciplinary cancer } \\
\text { care processes. }\end{array}$ \\
\hline Unclear models of care & - Develop clear processes and patient pathways for care in each national context. \\
\hline $\begin{array}{l}\text { Inadequate physical capacity } \\
\text { and resourcing in hospitals }\end{array}$ & $\begin{array}{l}\text { - Ensure adequate hospital capacity and resources for delivery of radioligand therapy to meet current and } \\
\text { future demand. }\end{array}$ \\
\hline Evolving legislation, regulation and policy & $\begin{array}{l}\text { - Incorporate radioligand therapy into national, regional and local cancer plans. } \\
\text { - Establish clear, consistent regulatory frameworks for the use of radioisotopes spanning approval, funding } \\
\text { and reimbursement. } \\
\text { - Ensure continued supply and appropriate disposal policies. }\end{array}$ \\
\hline Lack of data and research & $\begin{array}{l}\text { - Invest in real-world data on radioligand therapy to better understand patient outcomes and cost-- } \\
\text { effectiveness. } \\
\text { - Identify and share best practices to optimise and standardise care. }\end{array}$ \\
\hline
\end{tabular}

therapy is an important challenge [5, 12, 24, 25]. Analysis of existing clinical trial data may be hindered by the heterogeneity of patient groups with advanced cancer and the retrospective nature of the data $[5,12]$. In the field of neuroendocrine tumours, the low number of people affected presents an additional barrier. More real-world data reflecting the longer-term experience of patients on radioligand therapy is needed to improve our understanding of the therapy's impact on patient outcomes and resource use, and guide future use of this approach.

\section{The way forward}

As for any evolving treatment modality, it will take concerted effort and the alignment of multiple factors for radioligand therapy to be properly integrated into cancer care. A shift towards multidisciplinary working and re-evaluation of discrete, independent health specialties is essential — not just for radioligand therapy but for all cancer treatment.

The report proposes 10 key actions to be taken to help overcome existing barriers (Table 1). These will require concerted action by multiple stakeholders including decisionmakers, nuclear medicine professionals and the broader cancer clinical community, hospital managers, patient organisations, researchers and industry.

\section{Conclusions}

Radioligand therapy may provide life-enhancing treatment for patients with cancer who have limited therapeutic options. To ensure it can be appropriately embedded into cancer care, greater integration of nuclear medicine into models of care, workforce planning and hospital resourcing is needed [14, 15, 26]. At a policy level, the inclusion of radioligand therapy in cancer-related policies and future cancer plans - such as Europe's Beating Cancer Plan_—will also be essential, as will be proactively addressing healthcare system capacity issues to enable the provision of safe, high-quality care for both inpatients and outpatients across settings.

Acknowledgments The Health Policy Partnership gratefully acknowledges the invaluable contributions of the following experts who provided their insights to the project in interviews and personal communications:

- Dr. Annibale Versari, Director, Oncology and Advanced Technologies, ASMN Reggio Emilia, Italy

- Dr. Harald Lahner, Deputy Director, ENETS Center of Excellence, University Hospital Essen, Germany

- Dr. John Buscombe, President, British Nuclear Medicine Society, UK

- Dr. Valentina Ambrosini, Associate Professor of Nuclear Medicine, University of Bologna, Italy

Additional thanks to the steering committee members, who provided additional time and expertise to the project:

- Dr. Josep Maria Borras, Director, Catalonia Cancer Strategy, Spain

Funding information This editorial is based on the findings of a report produced by The Health Policy Partnership, with funding provided by a grant from Advanced Accelerator Applications, a Novartis Company, with additional support from Curium. Only authors from The Health Policy Partnership were paid; no other authors were paid for their time.

The report and report summary can be found on the project website www.radioligandtherapy.com. 


\section{Compliance with ethical standards}

Conflicts of interest The authors declare the following financial interests/personal relationships which may be considered as potential competing interests: CM, CW and SW are employees of The Health Policy Partnership, which has received funding from Advanced Accelerator Applications, a Novartis Company, and from and Curium to coordinate this work on behalf of the independent and unpaid coauthors, in addition to a research report, report summary, animation and microsite on the topic of radioligand therapy. NJ has received Nurse Education Programme Organising Committee Honoraria from Ipsen UK. NJ is an employee of Neuroendocrine Cancer UK, which receives project grants and honoraria for advisory boards and speaking engagements from Ipsen, Novartis, ITM and MERCK. KH reports personal fees from Bayer, other from Sofie Biosciences, personal fees from SIRTEX, non-financial support from $\mathrm{ABX}$, personal fees from Adacap, personal fees from Curium, personal fees from Endocyte, grants and personal fees from BTG, personal fees from Ipsen, personal fees from Siemens Healthineers, personal fees from GE Healthcare, personal fees from Amgen, personal fees from Novartis, personal fees from ymabs, outside the submitted work. AC reports speaker's honoraria from AAA, General Electric; travel grants from General Electric, SIRTEX; advisory board honoraria from Blue Earth Diagnostics, AAA; unconditional scientific support from Sanofi Genzyme; all outside the submitted work.

Informed consent Not applicable.

Ethical approval Institutional Review Board approval does not apply because the paper is an Editorial.

Study subjects or cohorts overlap Not applicable.

Methodology Not applicable.

Open Access This article is licensed under a Creative Commons Attribution 4.0 International License, which permits use, sharing, adaptation, distribution and reproduction in any medium or format, as long as you give appropriate credit to the original author(s) and the source, provide a link to the Creative Commons licence, and indicate if changes were made. The images or other third party material in this article are included in the article's Creative Commons licence, unless indicated otherwise in a credit line to the material. If material is not included in the article's Creative Commons licence and your intended use is not permitted by statutory regulation or exceeds the permitted use, you will need to obtain permission directly from the copyright holder. To view a copy of this licence, visit http://creativecommons.org/licenses/by/4.0/.

\section{References}

1. European Medicines Agency. Xofigo: EPAR - medicine overview. In: Xofigo. 2018. https://www.ema.europa.eu/en/documents/ overview/xofigo-epar-medicine-overview_en.pdf. Accessed 10/ $01 / 20$.

2. European Medicines Agency. Lutathera: EPAR - Summary for the public. In: Lutathera. 2018. https://www.ema.europa.eu/en/ documents/overview/lutathera-epar-summary-public_en.pdf. Accessed 02/04/19.

3. Baum RP, Kulkarni HR, Singh A, Kaemmerer D, Mueller D, Prasad V, et al. Results and adverse events of personalized peptide receptor radionuclide therapy with (90)Yttrium and (177)Lutetium in 1048 patients with neuroendocrine neoplasms. Oncotarget. 2018;9:16932-50. https://doi.org/10.18632/oncotarget.24524.

4. Nilsson S. Radionuclide therapies in prostate cancer: integrating radium-223 in the treatment of patients with metastatic castrationresistant prostate cancer. Curr Oncol Rep. 2016;18:14. https://doi. org/10.1007/s11912-015-0495-4.

5. Virgolini I, Decristoforo C, Haug A, Fanti S, Uprimny C. Current status of theranostics in prostate cancer. Eur J Nucl Med Mol Imaging. 2018;45:471-95. https://doi.org/10.1007/s00259-017$3882-2$.

6. Strosberg J, Wolin E, Chasen B, Kulke M, Bushnell D, Caplin M, et al. Health-related quality of life in patients with progressive midgut neuroendocrine tumors treated with (177)Lu-Dotatate in the phase III NETTER-1 trial. J Clin Oncol. 2018;36:2578-84. https://doi.org/10.1200/jco.2018.78.5865.

7. Strosberg J, El-Haddad G, Wolin E, Hendifar A, Yao J, Chasen B, et al. Phase 3 trial of (177)Lu-Dotatate for midgut neuroendocrine tumors. N Engl J Med. 2017;376:125-35. https://doi.org/10.1056/ NEJMoa1607427.

8. Zimmermann RG. Why are investors not interested in my radiotracer? The industrial and regulatory constraints in the development of radiopharmaceuticals. Nucl Med Biol. 2013;40:155-66. https:// doi.org/10.1016/j.nucmedbio.2012.10.012.

9. The Health Policy Partnership. Radioligand therapy: realising the potential of targeted cancer care. London: The Health Policy Partnership; 2020.

10. Fahey F, Zukotynski K, Capala J, Knight N. Targeted radionuclide therapy: proceedings of a joint workshop hosted by the National Cancer Institute and the Society of Nuclear Medicine and Molecular Imaging. J Nucl Med. 2014;55:337-48. https://doi.org/ 10.2967/jnumed.113.135178.

11. Parker C, Lewington V, Shore N, Kratochwil C, Levy M, Linden O, et al. Targeted alpha therapy, an emerging class of cancer agents: a review. JAMA Oncol. 2018;4:1765-72. https://doi.org/10.1001/ jamaoncol.2018.4044.

12. Bodei L, Kidd M, Baum RP, Modlin IM. PRRT: defining the paradigm shift to achieve standardization and individualization. J Nucl Med. 2014;55:1753-6. https://doi.org/10.2967/jnumed.114. 143974

13. Sartor AO, Fitzpatrick JM. Urologists and oncologists: adapting to a new treatment paradigm in castration-resistant prostate cancer (CRPC). BJU Int. 2012;110:328-35. https://doi.org/10.1111/j. 1464-410X.2011.10818.x.

14. Abbott A, Sakellis CG, Andersen E, Kuzuhara Y, Gilbert L, Boyle $\mathrm{K}$, et al. Guidance on (177)Lu-DOTATATE peptide receptor radionuclide therapy from the experience of a single nuclear medicine division. J Nucl Med Technol. 2018;46:237-44. https://doi.org/10. 2967/jnmt.118.209148.

15. Du Y, Carrio I, De Vincentis G, Fanti S, Ilhan H, Mommsen C, et al. Practical recommendations for radium-223 treatment of metastatic castration-resistant prostate cancer. Eur J Nucl Med Mol Imaging. 2017;44:1671-8. https://doi.org/10.1007/s00259-017-3756-7.

16. Sharma S, Baldi A, Singh R, Sharma R, Sharma RK. Regulatory framework of radiopharmaceuticals: current status and future recommendations. Res J Pharm Biol Chem Sci. 2018;4:275-90. https://doi.org/10.26479/2018.0403.25.

17. Kim SJ, Pak K, Koo PJ, Kwak JJ, Chang S. The efficacy of (177)Lu-labelled peptide receptor radionuclide therapy in patients with neuroendocrine tumours: a meta-analysis. Eur J Nucl Med Mol Imaging. 2015;42:1964-70. https://doi.org/10.1007/s00259015-3155-x.

18. OECD Nuclear Energy Agency. The supply of medical radioisotopes: 2019 medical isotope demand and capacity projection for the 2019-2024 period. Paris: The Organisation for Economic Cooperation and Development (OECD); 2019. 
19. European Commission. Supply of medical radioisotopes. In: Nuclear Observatory. 2019. https://ec.europa.eu/euratom/ observatory_radioisotopes.html. Accessed 06/12/19.

20. European Commission. Preliminary report on supply of radioisotopes for medical use and current developments in nuclear medicine. In: Health and Consumers Directorate-General, Public Health and Risk Assessment: Health threats. 2009. https://ec.europa.eu/ euratom/docs/2009 radioisotopes report en.pdf. Accessed 20/02/ 2020.

21. OECD Nucelar Energy Agency. The supply of medical radioisotopes: an economic study of the molybdenum-99 supply chain. Paris: The Organisation for Economic Co-operation and Development (OECD); 2010.

22. Rahbar K, Afshar-Oromieh A, Jadvar H, Ahmadzadehfar H. PSMA Theranostics: current status and future directions. Mol Imaging. 2018;17:1536012118776068. https://doi.org/10.1177/ 1536012118776068 .
23. Turner JH. Recent advances in theranostics and challenges for the future. Br J Radiol. 2018;91:20170893. https://doi.org/10.1259/bjr. 20170893.

24. Jadvar H. Targeted radionuclide therapy: an evolution toward precision cancer treatment. AJR Am J Roentgenol. 2017;209:277-88. https://doi.org/10.2214/ajr.17.18264.

25. Sowa-Staszczak A, Chrzan R, Pach D, Stefańska A, Tomaszuk M, Buziak-Bereza M, et al. Are RECIST criteria sufficient to assess response to therapy in neuroendocrine tumors? Clin Imaging. 2012;36:360-4. https://doi.org/10.1016/j.clinimag.2011.11.005.

26. Kasi PM, Maige CL, Shahjehan F, Rodgers JM, Aloszka DL, Ritter A, et al. A care process model to deliver (177)Lu-Dotatate peptide receptor radionuclide therapy for patients with neuroendocrine tumors. Front Oncol. 2018;8:663. https://doi.org/10.3389/fonc.2018. 00663.

Publisher's note Springer Nature remains neutral with regard to jurisdictional claims in published maps and institutional affiliations. 